\title{
A Model of Peer-to-Peer (P2P) Social Lending in the Presence of Identification Bias
}

\author{
Frederick J. Riggins \\ Arizona State University \\ W.P. Carey School of Business \\ Tempe, AZ 85287 USA \\ 1-480-727-9307 \\ fred.riggins@asu.edu
}

\author{
David M. Weber \\ Arizona State University \\ W.P. Carey School of Business \\ Tempe, AZ 85287 USA \\ 1-480-965-3252 \\ dmweber@asu.edu
}

\begin{abstract}
The Internet has created new opportunities for peer-to-peer (P2P) social lending platforms to emerge which have the potential to transform the way microfinance institutions (MFIs) raise and allocate funds used for poverty reduction. Depending upon where decision making rights are allocated, there is the potential for identification bias whereby lenders may be motivated to give to specific projects with which they have a personal interest or affinity without regard to whether or not it represents a particularly sound financial investment. In this paper, we present an analytical model where an individual lender can use a P2P social lending network to provide funds to entrepreneurs seeking funding in developing nations. We show that in the presence of identification bias, the P2P social lending network can be used to increase overall contributions for poverty reduction despite the fact that such a network may result in inefficient allocation of funds. Even so, in the presence of strong identification bias this inefficient mechanism can result in improved poverty reduction through the provisioning of financial services in the microfinance industry.
\end{abstract}

\section{Keywords}

Microfinance, peer-to-peer (P2P) networks, identification bias, analytical model, decision making rights, poverty reduction.

\section{INTRODUCTION}

The emergence of the microfinance industry over the past few decades is an important economic phenomenon for promoting economic development. Muhammad Yunas was awarded the 2006 Nobel Peace Prize for his efforts in founding the Grameen Bank and his pioneering role in developing many microfinance concepts [30, 31]. Microfinance has been defined as "the provision of financial services to poor or low-income clients, including consumers and the self-employed" [17]. While these services can include a range of banking-related services, a key component is microcredit or microlending which involves the provisioning of small loans to clients, many of whom are small entrepreneurs who seek sources of funding to grow their business [2]. Grameen Bank and other non-profit lending organizations are non-government organizations (NGOs) that are typically referred to as microfinance institutions (MFIs). While their objectives can vary, most MFIs usually provide financial services to the poor with an outreach objective rather than a profit objective [13].

In addition to microfinance, information and communications technology (ICT) is another important enabler of economic development in developing nations [7, 29]. The United Nations' eighth Millennium Development Goal is to "develop a global partnership for development," and includes the target objective to "in cooperation with the private sector, make available the benefits of new technologies, especially information and communications" (www.un.org/millenniumgoals/). ICT can allow organizations that provide various services in remote regions, such as medical services and financial services, to extend their reach to new geographical locations thereby improving socioeconomic conditions in areas that previously were not served. Also, the efficiency benefits from ICT that western businesses and organizations have enjoyed are now being made available to similar parties in developing nations.

This research examines the intersection of these two global development phenomena - microfinance and ICT - where information and communications technology is viewed by many as a transformational and disruptive technology that creates opportunities and challenges to MFIs seeking to provide financial services to the world's poor [13]. It is at this intersection that new industry players are using ICT to alter the role of existing MFIs in the industry. For example, information intermediaries, such as the Microfinance Information Exchange (also known as MIX Market, www.mixmarket.org), bring increased visibility in the microfinance industry that can help potential donors and investors know which MFIs are a good investment vehicle. These infomediaries play an important role in the information value chain, but typically don't take possession of, or transfer, funds.

On the other hand, other ICT-enabled intermediaries are peer-topeer (P2P) social lending platform providers who deliver both information and money transfers between MFIs and individual western lenders. These P2P platforms open up new opportunities to entrepreneurs in poor developing countries by linking them to western, philanthropically-minded microlenders. A well-known and growing example is Kiva (www.kiva.org) where individual western lenders can view a number of loan requests from entrepreneurs from around the globe and can quickly make microloans in increments of \$25 using their PayPal account. This new model results in an increased level of personalization and transparency which allows individual western lenders to specify who should receive capital for a loan request based on the description of the loan, an image, name, biography, and gender of the entrepreneur, and the name and location of the MFI administering the loan.

These P2P social lending platforms differ from other types of philanthropic mechanisms in a number of ways. First, decision rights on where specific funds should be directed are often transferred directly to the lender. In most relief and development 
situations the agency on the ground in the developing region has better knowledge of the particular needs of the local economy and how funds can best be put to use based on the idiosyncratic local economic situation. In P2P social lending sites, the western-based lender often does not have such knowledge of the local economy. Also, P2P social lending sites provide a much closer personal link between the person providing funds for development and the recipient seeking the funds. The rich media that can be used over the Internet allows the lender to identify closely with the recipient's life situation which may create biases in the lender/borrower relationship. Because the lender receives specific information provided by the borrower and the P2P social lending site, the lender doesn't just lack knowledge of the local economy; the information he or she does have receive be skewed to favor the individual seeking funding.

When individual western lenders using P2P social lending sites are allowed decision making rights regarding who receives microloans in distant countries, a number of important questions emerge regarding the efficiencies of this model:

- Do individual western lenders have the knowledge they need to make informed investment decisions in far away locations or should these allocation decisions be made by MFIs who may have a better understanding of local business and economic conditions?

- What are the implications of the presence of identification bias where individual western lenders using rich-media P2P social lending platforms can make microloans to distant entrepreneurs with whom they have a natural affinity or where they identify with the theme of the specific entrepreneurial project?

- Within the context of the microfinance value chain, does allocating decision-making rights with the downstream MFIs versus the upstream lender have implications for the efficiency of the microlending process?

In this paper, we present an analytical model where an individual western lender can use a P2P social lending network to provide funds to entrepreneurs seeking funding in developing nations. We show that in the presence of identification bias the P2P social lending network can result in an inefficient allocation of funds where the lender has an incentive to make microloans to projects where there is an affinity with the type of project or characteristics of the borrower. However, we also show that despite this inefficiency, the identification bias may result in an increase in the overall contribution of microloans which ultimately may result in improved poverty reduction and the provisioning of financial services in the microfinance industry.

\section{P2P SOCIAL LENDING}

Giving to charitable causes can be motivated by a number of factors that have been studied over the past fifty years. Economic literature on philanthropy notes that altruism, exchange, and warm glow (psychological benefit) are strong motivators for charitable giving [21]. Bekkers and Wiepking [3] provide an extensive literature review of over 500 articles published on philanthropic motivation and ultimately identify eight different mechanisms that can drive charitable giving:

1) awareness of need is typically a prerequisite for giving,

2) solicitation and the way people are asked to give,
3) costs and benefits as they relate to the expected impact of giving,

4) altruism and a genuine interest in the cause,

5) reputation of the donor,

6) psychological benefits related to a "warm glow" and the impact on self-image,

7) values and a desire to see one's values promulgated, and

8) efficacy and the view that their contributions truly matter.

In this study, we are most interested in the impact of P2P social network lending which can impact a number of these factors. For example, identification bias could be viewed as a type of altruism based on an interest in the cause or as another type of psychological benefit beyond warm glow. In particular, identification bias is based on the ability to identify with the recipient of the loan. Within the above framework explained by Bekkers and Wiepking [3], this would fall under the influence of reputation. Giving is increased when the giver likes the recipient [4]. Even if there is no particular relationship between the giver and recipient, studies have shown that even a brief dialogue and interaction can increase contributions since this increases the chances of liking $[8,9,18]$. Ultimately, liking of the solicitor enhances the reputation of the contributor since it increases the value of approval received by donors, which may be viewed by the contributor as increasing perceived reputation.

While many of the studies on philanthropic giving are empirical studies examining a number of factors, there has been considerable work done using analytical modeling to understand the impacts of these different factors. Andreoni [1] introduces an analytical model of impure altruism that attempts to model the economics of the crowding out effect which could occur if charitable causes are funded, in part, through public government contributions. Roberts [22] similarly models the impact on charitable contributions of government funding aimed at the poor (see also [28]). Other examples of analytical models of giving includes Hatsumi [11] who models the impact of giving when seed money is provided as start-up capital. In this paper, we apply similar concepts to the potential identification bias benefit that can occur in P2P social lending networks.

Microfinance has been instrumental in helping alleviate poor in developing countries, often where traditional banks choose not to provide financial services to the poorest and most geographically distant parts of the population. Often MFIs focus on providing small entrepreneurs the needed capital via microloans to launch or improve their business. In 2004 it was estimated that there were nearly 100 million microcredit borrowers benefiting from MFI outreach programs $[5,20]$. Overall it has been estimated that MFIs provide some form of financial service that benefit about a half a billion poor and low-income people globally [6]. Poor populations in developing countries have been neglected by traditional financial services organizations for a number of reasons. To traditional banks, the poor may be difficult to reach geographically, require high operating costs in the provision of services, and typically represent a higher financial risk [2]. Because the poor usually have little or no collateral, no credit history, and little or no experience handling money or running a business they are viewed by traditional banks as more risky clientele. Distant rural markets are operationally difficult to serve, 
have low population density and their borrowers require smaller, less profitable transactions $[19,25]$.

Pioneers in the microfinance industry have developed a number of approaches that have helped to mitigate some of this risk [6]. MFIs often use group lending techniques that use peer pressure from other group members to increase accountability and motivation for loan repayment. Individuals make small loan repayments within the context of the group at group meetings. Further lending to group members is predicated on all group members' loan repayment activities. In addition to group lending, MFIs are more likely to provide microloans to women where the evidence suggests that females are more likely to use the funds more responsibly than men. Also, providing business advice and consulting to small entrepreneurs can increase likelihood of success and loan repayment. Because of these innovations, MFIs that are typically located in the same city or village as the entrepreneur usually possess a good deal of knowledge about the performance potential of loan requests in terms of likelihood for business success, loan repayment potential, and ultimately the impact on poverty reduction.

Currently, many players across the microfinance value chain are using ICT for transformational changes in the industry [13]. MFIs are using ICT-based analytical tools to determine which loan request projects have better chances for success and therefore better repayment rates. Also, they can use ICT to extend the reach of their services to more distant, remote locations. Internally, MFIs are utilizing ICT to improve operational efficiencies which is essential in an increasingly competitive environment. Finally, ICT is being used by organizations like Mix Market to increase the level of transparency of MFI operations and risk to potential donors and investors. This improvement in transparency should result in higher levels of funding from these individuals and groups in the upstream portion of the value chain.

Peer-to-peer social networks such as Facebook, LinkedIn, Twitter, and Flickr have become a powerful part of the typical Internet user's online experience. The ability to connect with like-minded individuals on a rich media $\mathrm{P} 2 \mathrm{P}$ platform, regardless of geographical location, allows people to enhance existing relationships, create new relationships, and share their stories in ways that were not feasible until recently. In a similar fashion P2P social lending networks allow small entrepreneurs in developing nations to connect with individual western lenders to share their stories and seek new sources of funding. These P2P social lending networks currently work mostly in conjunction with existing MFIs where the microfinance institution determines which entrepreneur's loan request will be posted on the P2P social lending network. We believe these $\mathrm{P} 2 \mathrm{P}$ networks have the potential to radically transform the way MFIs operate because they open up an entirely new source of funds origination - the individual western lender - as opposed to relying mostly on larger philanthropic givers and organizations.

Kiva is the largest and best known international P2P social lending network. Kiva, Swahili for 'unity', was incorporated in 2005 and has facilitated over \$130 million in loans to 331,000 borrowers [14]. On Kiva.org an individual western lender can observe a number of individual loan requests from nations around the globe. Each loan request provides a picture and description of the entrepreneur and his/her business, the specifics of the project loan request, proposed loan repayment terms, and other information that might be of interest to the lender. These loan requests cover a wide range of small business needs - from a request for $\$ 650$ for new sewing machines for a women entrepreneur in Ivory Coast to $\$ 1,200$ so a farmer in Chad can buy five additional goats. Individual western lenders can choose which project to help fund and join a group of lenders by contributing funds in \$25 increments using PayPal. Other smaller examples of international P2P social lending networks include Global Giving, Wokai, Microplace, Zidisha, and MyC4. In addition, P2P social lending networks in the U.S. market include Prosper.com and LendingClub.com. These domestic networks are subject to greater regulations, but the lending concept is similar people needing loans get a chance to tell their story so that people with financial assets might take an interest in the project and provide small loan amounts.

In addition to the philanthropic motivations mentioned earlier, identification theory is defined and used by Schervish and Herman [24] in a study of the giving motivations for 130 millionaires. This study found that philanthropy is a manifestation of providing care and the major impetus for philanthropy is identification with others and their needs. Individuals recognize that the situational context of others is similar to their own in terms of their lives, needs, or experiences. Meeting needs of individuals where identification links exist elicits satisfaction on the part of charitable individuals $[12,23]$. This seems to be an important motivation for P2P social lending and is made explicit on sites like Kiva.org where entrepreneurs can tell their story to prospective lenders.

While the majority of P2P social lenders receive their capital investments returned to them in full, intermediaries like Kiva do not allow lenders to receive any of the interest that borrowers incur when repaying their loans to the administering MFIs. Particularly when there is no potential for financial gain through interest we believe that identification theory provides a useful lens on the motivation of lenders in this context. Identification theory states that identification with borrowers, rather than the specific MFI goal of poverty reduction, is the most influential factor for lenders when making charitable lending decisions. P2P social lending is a unique charitable model since it provides a direct connection between donors (lenders) and the lives they wish to change (borrowers). In donations to other aid organizations like United Way or Salvation Army, the donor is usually uninvolved in determining where his or her donation will be allocated. With P2P social lending, the allocation of decision rights to the lender provides greater opportunity for identification with borrowers which likely plays a key role in funding decisions.

Studies on philanthropy conclude that solicitations that identify specific beneficiaries are more likely to result in contributions $[15,16]$. These same authors also show that information about a single recipient is more effective than information about multiple unidentified people in need. Further, the provisioning of specific information and statistics about the plight of the prospective beneficiary also increases contributions [26, 27].

In the next section, we develop a model where an individual western lender can use a P2P social lending network to provide funds to entrepreneurs seeking funding in developing nations. Specifically, we examine the implications of identification bias and the allocation of decision making rights upstream in the value chain. 


\section{THE BASIC MODEL}

Consider an economy with one private good, which we will refer to as going to the movies, and two public goods, projects $\mathrm{A}$ and $\mathrm{B}$ which are entrepreneurial investment projects in the developing world. Individuals are endowed with wealth, $w_{i}$, which is fixed and can be allocated between consumption of the private good, $x_{i}$, and investment in the two projects, $y_{\mathrm{A} i}$ and $y_{\mathrm{B} i}$, where $Y_{i}=y_{\mathrm{A} i}+y_{\mathrm{B} i}$, and $w_{i}=x_{i}+Y_{i}$. We will view this as a sequential decision where the individual decides how much to give to the projects and how much to spend on the movies, followed by the decision about how to allocate the contributions between the two projects. We will begin by considering the project allocation decision.

Individual, $i$, gains an altruistic benefit $U_{\mathrm{Ai}}\left(y_{\mathrm{A} i}\right)$ from investing $y_{\mathrm{A} i}$ in project A where $U_{\underline{\mathrm{A}} i}$ is strictly increasingly quasi-concave in $y_{\mathrm{A} i}$ and is subject to the idiosyncratic aspects of the project that make it a particularly promising investment or not. The same assumption holds for $U_{\mathrm{Bi}}\left(y_{\mathrm{B} i}\right)$. In addition to the altruistic benefit, the individual can receive an identification bias benefit when the individual has a particular identification or affinity for the particular project. For example, a farmer in the Upper Midwest may enjoy loaning to a goat herder who desires to use the money to buy three new goats for his small agricultural milking operation (project A), while a librarian in the Pacific Northwest may desire to loan money to a small book seller who desires to upgrade his small store by adding a reading room (project B).

We assume the two projects are located on the end points of a Hotelling model line as shown in Figure 1 where A represents the agricultural project and B represents the book seller project. Individuals are located uniformly along the line, where individual, $i$, is located on the line at $z_{i}$, where $z_{i} \subset[0,1]$, such that he or she may have a strong identification bias with one project over the other. Assume that the identification bias benefits for individual $i$ investing in projects $\mathrm{A}$ and $\mathrm{B}$ respectively are $y_{\mathrm{A} i} t\left(1-z_{i}\right)^{2}$ and $y_{\mathrm{B} i}$ $t\left(z_{i}\right)^{2}$ where $t$ is the usual Hotelling model transportation cost parameter, or in this case, the disutility from not fully identifying with a particular project. We use the quadratic function which is a common approach with Hotelling models to capture the convexity of the identification bias. Notice that $t$, where $t \geq 0$, is a measure of the strength of the identification bias such that when $t=0$ there is no identification bias benefit. Further note that when $z_{i}=.5$ individual $i$ is indifferent between the two projects in terms of the identification bias benefit.

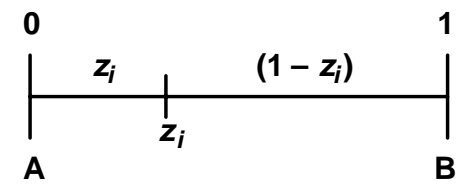

Figure 1. Hotelling Model of Two Project Options

The full model can be written as

$$
\begin{gathered}
\max _{x_{i}, y_{\mathrm{A} i}, y_{\mathrm{Bi}}} U_{\mathrm{A}}\left(y_{\mathrm{A} i}\right)+y_{\mathrm{A} i} t\left(1-z_{i}\right)^{2}-y_{\mathrm{A} i}+U_{\mathrm{B}}\left(y_{\mathrm{Bi}}\right) \\
+y_{\mathrm{Bi}} t\left(z_{i}\right)^{2}-y_{\mathrm{B} i}+U\left(x_{i}\right)-x_{i} \\
\text { s.t. } y_{\mathrm{A} i}+y_{\mathrm{B} i}+x_{i}=w_{i} .
\end{gathered}
$$

$$
\begin{gathered}
\max _{x_{i}, Y_{i}} G\left(Y_{i}, t, z_{i}\right)-Y_{i}+U\left(x_{i}\right)-x_{i} \\
\text { s.t. } Y_{i}+x_{i}=w_{i}
\end{gathered}
$$

where $G\left(Y_{i}, t, z_{i}\right)$ is the utility the lender gets from lending to the projects and is increasingly concave in $Y_{i}$. We will examine the details of $G$ shortly, but first we can substitute $Y_{i}=w_{i}-x_{i}$ into the objective function to make it

$$
\max _{x_{i}} G\left(w_{i}-x_{i}, t, z_{i}\right)+U\left(x_{i}\right)-w_{i}
$$

and solve the first order condition to get

$$
\frac{\partial G\left(w_{i}-x_{i}, t, z_{i}\right)}{\partial x_{i}}+\frac{\partial U\left(x_{i}\right)}{\partial x_{i}}=0
$$

which is the usual result that the lender will equate the marginal benefit of giving an additional dollar to the charitable projects and the marginal benefit of paying another dollar to go to the movies. We now turn our attention to examining the specifics of $G\left(Y_{i}, t, z_{i}\right)$.

From (1) we see that when the lender is given decision making rights regarding the allocation of $Y_{i}$ between project A and project $\mathrm{B}$, he will solve the problem

$$
\begin{array}{cc}
\max _{y_{\mathrm{A} i}, y_{\mathrm{B} i}} & U_{\mathrm{A}}\left(y_{\mathrm{A} i}\right)+y_{\mathrm{A} i} t\left(1-z_{i}\right)^{2}-y_{\mathrm{A} i} \\
& +U_{\mathrm{B}}\left(y_{\mathrm{Bi}}\right)+y_{\mathrm{Bi}} t\left(z_{i}\right)^{2}-y_{\mathrm{Bi}} \\
& \text { s.t. } Y_{i}=y_{\mathrm{A} i}+y_{\mathrm{B} i} .
\end{array}
$$

Similar to the step above, we can use $y_{\mathrm{B} i}=Y_{i}-y_{\mathrm{A} i}$ and solve the first order condition to get

$$
\frac{\partial U_{\mathrm{A}}\left(y_{\mathrm{A} i}\right)}{\partial y_{\mathrm{A} i}}+t\left(1-2 z_{i}\right)=\frac{\partial U_{\mathrm{B}}\left(y_{\mathrm{B} i}\right)}{\partial y_{\mathrm{B} i}} .
$$

Consider the case where there is no identification bias benefit, i.e. $t=0$. If the lender had good information about the relative merits of each project and their likelihood of success he would equate the marginal benefits of giving an additional dollar to project and maximize total utility from the project outcomes according to (9). Unfortunately, the individual western lender typically would not have such information. Even if the MFI did have that information, there is no indication that P2P social lending platforms such as Kiva provide that type of project visibility to the prospective lender. In the absence of such information, and in the absence of identification bias benefit, the lender's best option is to give $Y_{i} / 2$ to each project. Except in the special case where $U_{\mathrm{A}}=U_{\mathrm{B}}$, this would be a misallocation of funds. The situation is illustrated in Figure 2 with $U_{\mathrm{B}}>U_{\mathrm{A}}$. The optimal situation is that rather than invest $Y_{i} / 2$ in each project, the lender would shift funds from project $A$ to project $B$ until the marginal benefit of each is equal at $y_{\mathrm{A} i}{ }^{*}$ and $y_{\mathrm{B} i}{ }^{*}$.

Using $Y_{i}=y_{\mathrm{A} i}+y_{\mathrm{B} i}$, the problem can be rewritten as 


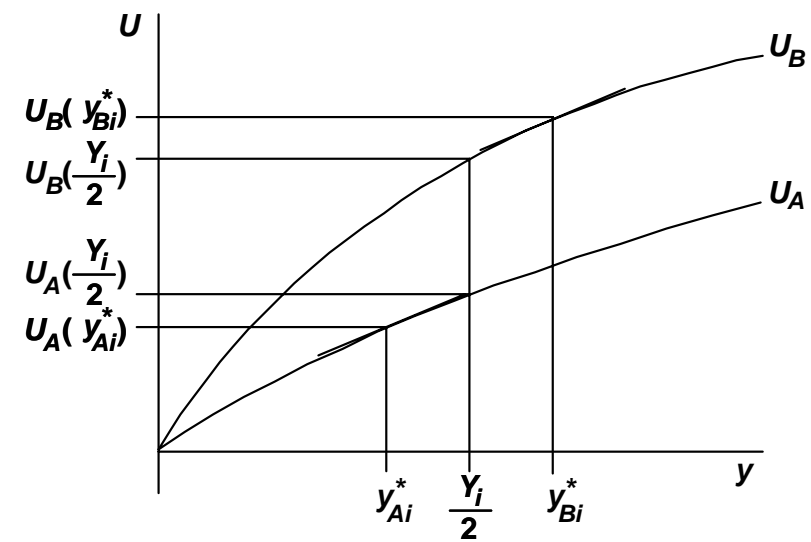

Figure 2. Funds Allocation in the Absence of Identification Bias Benefit

Now consider the result in (9) where $t>0$. First, notice that when $z_{i}=.5$ the lender is indifferent between the projects and will allocate as if $t=0$ (although identification bias benefit will be realized from both projects equally). However, when $0 \leq z_{i}<.5$ the lender prefers project $A$ and will increasingly shift funds from project B to project $\mathrm{A}$ as $z_{i}$ decreases. Similarly, when $.5<z_{i} \leq 1$ the lender prefers project $B$ and shifts funds to that project. It should be noted that even if the lender has full information about the relative merits of the projects, the identification bias benefit will still result in a misallocation of funds toward the more identifiable project.

Also, the reader should note that when $z_{i}=.5$ the total identification bias benefit is minimized but increases for individuals where $z_{i}$ is closer to 0 or 1 whereby funds are allocated towards the preferred project. Therefore, we see that as total identification bias benefit increases (i.e., when $z_{i} \rightarrow 0$ or $z_{i} \rightarrow 1$ ) total benefit from giving to fund entrepreneurial projects increases such that from (6) more funds will be given to fund projects in the developing world and less money being spent on going to the movies.

Finally, notice from (7), that when $t$ increases, the identification bias benefit is strictly increasing meaning that stronger identification bias will result in more funds being allocated to $Y_{i}$ and less money allocated to $x_{i}$ as shown in (6). In other words, stronger identification bias will result in more money going to fund entrepreneurial projects in the developing world and less money being spent on going to the movies.

\section{DISCUSSION}

The model presented in the previous section clearly shows that when decision-making rights are allocated to the individual western lender in P2P social lending networks there are several situations where there is likely to be an inefficient allocation of investment funds to projects in distant developing nations. First, when the lender has no information about the relative potential for success of the projects the funds will be misallocated. There should be an incentive for the MFI to provide the prospective lender with information about the relative merits of the projects. In most lending situations, the market-based interest rate of return is used as a signal to indicate to lender the relative risks of investing in the project. In P2P social lending sites like Kiva, interest is not returned to the lender - just the principle is repaid.
Also, there is little evidence these sites offer insights to the prospective lender about the merits of the projects. It is interesting to note that the MFIs determine which projects will be listed on Kiva and which will be funded using existing internal MFI funds. It could be that MFIs use Kiva to seek funding for projects they know carry relatively higher risk, and therefore would be reluctant to indicate this information on the Kiva site.

Inefficiency can also occur in that even if the prospective lender had full information about the likely outcome of the projects, misallocation of funds can still occur in the presence of identification bias. Despite the fact that more benefit can occur in the local developing nation when a particular project is funded and the lender has this as part of his or her objective function, having the additional objective of gaining identification bias benefit will incite the lender to misallocate funds in favor of the project with which he or she identifies. Indeed, if the MFI had knowledge of the lender's identification bias, the MFI might be inclined to misrepresent the potential for the two projects in order to "make up for" the lender's bias and subsequent misallocation. The reader can see that there is ample opportunity to motivate misinformation from the MFI through Kiva to the potential lenders.

Despite these inefficiencies, we also show that the inclusion of identification bias benefits in the lender's objective function may result in overall increased giving which is increasing in the strength of the bias - i.e., increasing $t$ and/or more relative identification $z_{i}<>.5$ with one project or the other. This increased funding of development projects occurs at the expense of consumption of the private good as more funds are used for charitable loans than going to the movies. Even when the funds are misallocated, in the presence of strong identification bias benefits the total local benefit in the developing country may be increased when decision-making rights are allocated to the distant individual western lender. So, even if the MFI knows which projects represent better chances for success and poverty reduction, in the presence of strong identification bias there may be an incentive to pass decision making rights further upstream and increase overall giving despite the inefficient allocation.

\section{CONCLUSION}

Taking advantage of the identification bias to increase funding for entrepreneurial projects in developing countries that otherwise may not have acquired funding seems to have been at the heart of the founding of Kiva.org in 2005. As founder Matt Flannery stated regarding the birth of Kiva

\footnotetext{
“... the human connections we build between lenders and borrowers have brought new lenders to the microfinance movement, and foster in them a new awareness and connection to the people who briefly use their money. By telling stories, we allow MFIs that lack access to capital markets to efficiently raise money and serve more clients" [10].
}

While P2P social lending networks may not take the place of MFIs anytime soon, it would appear that they play a critical albeit inefficient role as intermediaries between individual western lenders and MFIs working in developing countries.

This analysis opens up a number of opportunities for empirical investigation into the impact of ICT in the form of P2P social lending networks on the microfinance industry. The most obvious question would be to investigate whether or not microlending 
funding decision are biased by identification links between lenders and borrowers. Is the occupation of the lender a predictive factor in which types of projects the lender funds? Also, this analysis suggests that MFIs should try to provide objective information to prospective lenders on the relative merits of development projects which may or may not be taken into account by the lender depending upon the existence of identification bias. Does the amount and type of information provided by MFIs through Kiva impact their ability to fund successful loans? Finally, another empirical question relates to successful repayment of the loans. In particular, does loan repayment time and success represent a measure of the predictive relative merit of the project ex ante and does this seem to impact prospective lenders decision making process? In other words, do lenders who give to projects that they may have an affinity for see their loans repaid at a rate different from loans where there doesn't seem to be a measureable affinity?

These and other important questions need to be investigated both analytically and empirically as we seek to develop a theory of P2P social lending.

\section{ACKNOWLEDGMENTS}

We would like to thank Professors Jane Carey, Uday Kulkarni, and Rob Kauffman who have provided useful insights as we have developed the ideas in this paper. Also, we thank our colleagues in the Department of Information Systems at the W.P. Carey School of Business for their useful comments at our presentation in our weekly research workshop. Finally, Kiva.org has been instrumental in helping us understand the potential of P2P social lending networks.

\section{REFERENCES}

[1] Andreoni, J. 1990. Impure altruism and donations to public goods: a theory of warm-glow giving. The Econ. J., 100 (June 1990), 464-477.

[2] Armendariz de Aghion, B. and Morduch, J. 2005. The Economics of Microfinance, MIT Press, Cambridge, MA.

[3] Bekkers, R. and Wiepking, P. 2010. A literature review of empirical studies of philanthropy: eight mechanisms that drive charitable giving. Nonprofit and Voluntary Sector Qtrly, 20, 10 (2010), 1-50.

[4] Byrne, D. 1971. The Attraction Paradigm, New York: Academic Press.

[5] Christen, R.P., Rosenber, R., and Jayadeva, V. 2004. Financial institutions with a "double bottom line:" implications for the future of microfinance. C-GAP, Washington, DC.

[6] Cull, R., Demirguc-Kunt, A., and Morduch, J. 2009. Microfinance meets the market. J. Econ. Persp., 23, 1 (2009), 167-192.

[7] Dewan, S. and Riggins, F. J. 2005. The digital divide: current and future research directions. J. Ass. Info. Sys., 6, 9 (2005), 298-336.

[8] Dolinski, D., Grzyb, T., Olejnik, J., Prusakowski, S., \& Urban, K. 2005. Let's dialogue about penny: effectiveness of dialogue involvement and legitimizing paltry contribution techniques. J. of App. Soc. Psych., 35 (2005), 1150-1170.
[9] Dolinski, D., Nawrat, M., \& Rudak, I. (2001). Dialogue involvement as a social influence technique. Personality \& Soc. Psych. Bltn., 27 (2001), 1395-1406.

[10] Flannery, M. 2007. Kiva and the birth of person-to-person microfinance. Innovations, (Winter-Spring 2007), available at http://media.kiva.org/INNOV0201_flannery_kiva.pdf.

[11] Hatsumi, K. 2009. A Coordination Game Model of Charitable Giving and Seed Money Effect. Discussion paper no 736, April 2009 (Rev. Sept 2009), The Institute of Social and Economic Research, Osaka University, Japan.

[12] Havens, J. J., O’Herlihy, M. A., \& Schervish, P. G. 2007. Charitable giving: how much, by whom, to what, and how? In W. W. Powell \& R. S. Steinberg (Eds.), The non-profit sector: A research handbook (2nd ed). New Haven, CT: Yale University Press, 542-567.

[13] Kauffman, R.J. and Riggins, F.J. 2010. Research directions on the role and impact of ICT in microfinance. In Proc. of the Forty Third Ha.i Intl. Conf. on Sy. Sci. (Koloa, Kauai, HI January 05 - 08, 2010). hicss '10, 1-10. DOI= http://doi.ieeecomputersociety.org/10.1109/HICSS.2010.318

[14] Kiva 2010. Facts and History, http://www.kiva.org/about/facts. Page viewed on 9 April 2010.

[15] Kogut, T., and Ritov, I. 2005a. The "identified victim" effect: An identified group, or just a single individual? J. of Beh. Dec. Mak., 18 (2005), 157-167.

[16] Kogut, T., and Ritov, I. 2005b. The singularity effect of identified victims in separate and joint evaluations. Org. Behav. \& Human Dec. Processes, 97, 2 (2005), 106-116.

[17] Ledgerwood, J. 2000. Microfinance Handbook: An Institutional and Financial Perspective. The World Bank, Washington DC.

[18] Macaulay, J. (1975). Familiarity, attraction, and charity, Jrnl. of Social Psych., 95 (1975), 27-37.

[19] Mathison, S. 2005. Increasing the outreach and sustainability of microfinance through ICT innovation. In S. Mathison (ed.), Electronic Banking with the Poor: Increasing the Outreach and Sustainability of Microfinance through ICT Innovation, Foundation for Development Cooperation, Brisbane, Australia.

[20] Mersland, R. and Strom, R. O. 2009. Performance and governance in microfinance institutions. J. Bank. Fin., 33, 4 (April 2009), 662.

[21] Munnell, A.H. and Sunden, A.E. 2003. Death and Dollars: The Role of Gifts and Bequests in America. Washington, DC: The Brookings Press.

[22] Roberts, R.D. 1984. A positive model of private charity and public transfers. J. of Pol. Econ., 92 (1984), 136-148.

[23] Schervish, P. G., and Havens, J. J. 2002. The Boston area diary study and the moral citizenship of care. Voluntas, 13, 1 (2002), 47-71.

[24] Schervish, P.G. and Herman, A. 1988. The Study of Wealth and Philanthropy Final Report, Chesnut Hll, MA: Social Welfare Research Institute, Boston College.

[25] Singhal, A., and Duggal, B. 2005. Extending banking to the poor in India. In S. Mathison (ed.), Electronic Banking with 
the Poor: Increasing the Outreach and Sustainability of Microfinance through ICT Innovation, Fdtn. Dev. Coop., Brisbane, Australia.

[26] Small, D. A., and Loewenstein, G. 2003. Helping a victim or helping the victim: Altruism and identifiability. J. of Risk \& Uncertainty, 26, 1 (2003), 5-16.

[27] Small, D. A., Loewenstein, G., and Slovic, P. 2007. Sympathy and callousness: The impact of deliberative thought on donations to identifiable and statistical victims. Org. Behav. \& Human Dec. Processes, 102 (2007), 143-153.

[28] Warr, P. 1982. Pareto optimal redistribution and private charity. J. of Public Econ., 19 (1982), 131-138.
[29] Warschauer, M. 2004. Technology and Social Inclusion Rethinking the Digital Divide. The MIT Press, Cambridge, MA.

[30] Yunus, M. 2007a. Banker to the Poor: Micro-lending and the Battle against World Poverty. PublicAffairs, New York, NY.

[31] Yunus, M. 2007b. Creating a World Without Poverty: Social Business and the Future of Capitalism. PublicAffairs, New York, NY. 